\title{
STUDI KOMPARASI HASIL BELAJAR LINGKUNGAN HIDUP KELAS XI SMA PADA SEKOLAH ADIWIYATA DENGAN SEKOLAH NON ADIWIYATA DI KABUPATEN BULUKUMBA
}

\author{
COMPARATIVE STUDY OF THE RESULT OF ENVIRONMENT \\ STUDYING AT CLASS XI SMA AT ADIWIYATA SCHOOL AND NON \\ ADIWIYATA SCHOOL IN BULUKUMBA REGENCY
}

\author{
Jalil Ashar \\ Pendidikan Geografi, Matematika dan Ilmu Pengeathuan Alam \\ Program Pascasarjana Universitas Negeri Makassar \\ Jalil.ashar88@gmail.com
}

\begin{abstract}
This research was aimed: 1) to know the result of environment studying in school which do not apply adiwiyata program, 2) to know the result of environment studying in school which apply adiwiyata program, and 3) to analyze the significance of environment studying result between school which apply adiwiyata program and not. This research applied quantified approach. The kind of this research was non-experimental, with ex post facto design. The form of applied-design in this research was causal comparative studies. The result of the research showed: 1) the student's result in studying environment materials on non-adiwiyata school was in middle category, 2) the student's result in studying environment materials on adiwiyata school was in high category, and 3) there was significant differences between the student's result in studying environment materials at class XI on adiwiyata and non-adiwiyata school with $95 \%$ trusted-score.
\end{abstract}

Keyword: Adiwiyata, Comparative, Environment Studying

\begin{abstract}
Abstrak
Penelitian ini bertujuan untuk: 1) mengetahui hasil belajar lingkungan hidup pada sekolah yang tidak melaksanakan program adiwiyata, 2) mengetahui hasil belajar lingkungan hidup pada sekolah yang melaksanakan program adiwiyata, dan 3) menganalisis signifikansi hasil belajar lingkungan hidup antara sekolah yang melaksanakan dengan yang tidak melaksanakan program adiwiyata. Penelitian ini menggunakan pendekatan kuantitatif. Jenis penelitian ini adalah non eksperimen, dengan rancangan ex post facto. Bentuk rancangan yang dipakai adalah causal comparative studies. Hasil penelitian menunjukkan bahwa: 1) hasil belajar siswa pada materi lingkungan hidup sekolah non adiwiyata berada pada kategori hasil belajar sedang, 2) hasil belajar siswa pada materi lingkungan hidup sekolah adiwiyata berada pada kategori hasil belajar tinggi, dan 3) terdapat perbedaan yang signifikan antara hasil belajar lingkungan hidup pada siswa kelas XI pada sekolah adiwiyata dengan sekolah non adiwiyata pada taraf kepercayaan $95 \%$.
\end{abstract}

Kata Kunci : Adiwiyata, Komparatif, Belajar Lingkungan Hidup

\section{PENDAHULUAN}

Kepedulian terhadap lingkungan sekitar menjadi isu yang sangat hangat akhir-akhir ini. Masih ada di antara kita yang belum peduli dengan permasalahan lingkungan secara sungguh-sungguh. Cukup banyak ditemukan penanganan masalah lingkungan masih sebatas retorika dan administratif sehingga belum terwujud dalam tindakan nyata yang memadai. Hal ini sekaligus juga bermakna bahwa sesungguhnya kita tengah bunuh diri pelan-pelan secara ekologis. Beragam bencana lingkungan telah kita alami, namun bencana demi bencana tersebut ternyata hanya mampu mengingatkan kita sesaat saja. Upaya mencegah seakan tak pernah tersentuh oleh banyak ndividu. Perencanaan pencegahan lebih banyak terlupakan, kalaupun ada, terkesan dilakukan tidak maksimal. Program yang disiapkan lebih terpusat pada penanggulangan dampak bencana, bukan 
tindakan preventif terhadap kemungkinan terjadinya bencana. Studi terhadap kemungkinan terjadinya bencana dan langkah-langkah pencegahan munculnya permasalahan lingkungan seharusnya telah dilakukan sebelum bencana tersebut benarbenar melanda kehidupan kita [1].

Lingkungan hidup merupakan sesuatu yang penting unutuk dipelajari sebagai salah satu upaya preventif. Lingkungan hidup merupakan kesatuan ruang dengan semua benda, daya, keadaan, dan makhluk hidup termasuk manusia dan perilakunya sehingga tercipta suatu hubungan timbal balik dan saling mempengaruhi [2]. Pengelolaan lingkungan hidup merupakan upaya terpadu untuk melestarikan fungsi lingkungan hidup yang meliputi kebijaksanaan penataan, pemanfaatan, pengembangan, pemeliharaan, pemulihan, pengawasan, dan pengendalian lingkungan hidup [3]. Pendidikan lingkungan hidup memberikan latihan kepada anak didik berpikir secara serba cakup (comprehensif) mengenai segala gatra kehidupan manusia [4]. Sehingga dengan mempelajari pendidikan lingkungan, anak didik akan semakin menyatu dengan alam, dan semakin memahami fungsi alam tersebut dan bagaimana merawatnya demi menjaga keseimbangan. Program adiwiyata diharapkan dapat mengubah pola pikir generasi terhadap pentingnya keseimbangan lingkungan, sehingga apabila generasi sudah memahami dan mengerti tentang konsep keseimbangan lingkungan, maka besar kemungkinan akan dihasilkan calon-calon pemimpin yang mengerti dan melaksanakan konsep pembangunan berkelanjutan.

Bertitik dari permasalahan di atas maka peneliti merumuskan masalah sebagai berikut: 1) bagaimana hasil belajar lingkungan hidup pada sekolah yang tidak melaksanakan program adiwiyata?, 2) bagaimana hasil belajar lingkungan hidup pada sekolah yang melaksanakan program adiwiyata?, dan 3) bagaimanakah signifikansi hasil belajar lingkungan hidup antara sekolah yang melaksanakan dengan yang tidak melaksanakan program adiwiyata di Kab. Bulukumba?

Adapun tujuan penelitian yang ingin dicapai pada penelitian ini adalah untuk: 1) mengetahui hasil belajar lingkungan hidup pada sekolah yang tidak melaksanakan program adiwiyata, 2) mengetahui hasil belajar lingkungan hidup pada sekolah yang melaksanakan program adiwiyata, dan 3) menganalisis signifikansi hasil belajar lingkungan hidup antara sekolah yang melaksanakan dengan yang tidak melaksanakan program adiwiyata

\section{METODE PENELITIAN}

Penelitian ini menggunakan pendekatan kuantitatif. Jenis penelitian ini adalah non eksperimen, dengan rancangan ex post facto. Bentuk rancangan yang dipakai adalah causal comparative studies, rancangan penelitian ini sederhana. Penelitian komparatif adalah suatu penelitian yang bersifat membandingkan. Di sini variabelnya masih sama dengan penelitian variabel mandiri tetapi untuk sampel yang lebih dari satu atau dalam waktu yang berbeda [5]. Penulis membandingkan hasil belajar siswa kelas XI antara sekolah yang menerapkan program adiwiyata (SMA Negeri 6 Bulukumba) dengan sekolah yang belum menerapkan program adiwiyata (SMA Negeri 4 Bulukumba).

\section{HASIL PENELITIAN \\ Pelaksanaan Program Adiwiyata}

Program adiwiyata bertujuan mewujudkan warga sekolah yang memiliki tanggung jawab untuk mengelola dan melindungi lingkungan hidup melalui tata kelola sekolah yang baik untuk mendukung pembangunan berkelanjutan [6]. Pelaksanaan program adiwiyata dapat dikelompokkan menjadi empat komponen pelaksanaan yaitu kebijakan sekolah yang berwawasan lingkungan, pelaksanaan kurikulum berbasis lingkungan, kegiatan lingkungan berbasis partisipatif, dan pengelolaan sarana pendukung ramah lingkungan [7]. Berdasarkan hasil observasi 
dan penelaan berapa dokumen serta informasi dari pihak pelaksana program adiwiyata di sekolah ini dapat disimpulkan bahwa Kepala Sekolah SMA Negeri 6 Bulukumba telah memutuskan berapa kebijakan dalam rangka mewujudkan sekolah adiwiyata. Kebijakan yang telah ditetapkan dapat dilihat dari upaya perlindungan dan pengelolaan lingkungan hidup yang secara ringkas dapat dilihat dari uraian berikut: 1) visi, misi dan tujuan sekolah yang bebasis lingkungan hidup. 2) struktur KTSP mengkombinasi dengan pelajaran reintegrasi dengan lingkungan hidup. 3) bidang Kesiswaan merencanakan anggaran untuk kegiatan-kegiatan siswa terkait dengan pengelolaan dan perlindungan lingkungan. 4) sarana dan prasarana berupa penyediaan air bersih seperti kolam penampungan air bersih, sarana pengelolaan sampah seperti tempat sampah yang terpisah berdasarkan jenisnya, tempat sampah untuk pembuatan kompos, dan lingkungan sekolah yang memiliki pohon peneduh yang dapat dijadikan tempat untuk belajar yang nyaman untuk siswa. 5) Budaya lingkungan sekolah dilakukan dengan memasang slogan dan pamflet untuk hemat air.

\section{Hasil Belajar Sekolah Non Adiwiyata}

Kategori hasil belajar siswa pada sekolah non adiwiyata ini di sajikan pada tabel berikut:

Tabel 1. Distribusi Frekuensi Hasil Belajar Siswa pada Sekolah Non Adiwiyata

\begin{tabular}{ccccc}
\hline No & Interval & Kategori & Frekuensi & Persentase (\%) \\
\hline 1 & $90-100$ & Sangat tinggi & 1 & 3,33 \\
2 & $80-89$ & Tinggi & 7 & 23,33 \\
3 & $65-79$ & Sedang & 22 & 73,33 \\
4 & $55-64$ & Rendah & 0 & 0 \\
5 & $0-54$ & Sangat rendah & 0 & 0 \\
\hline \multicolumn{2}{l}{ Tabel di } & atas menunjukkan tingkat & \multicolumn{2}{c}{ Berdasarkan kriteria ketuntasan minimal } \\
pengetahuan & siswa & terhadap materi & (KKM) yang berlaku di SMA Negeri 4 \\
lingkungan hidup pada sekolah yang tidak & Bulukumba yakni 71, maka tingkat \\
menerapkan program adiwiyata. Sebanyak 1 & pencapaian KKM pada materi lingkungan \\
siswa atau 3,33\% mendapatkan nilai dengan & \multicolumn{2}{l}{ hidup dapat dilihat pada tabel 2 berikut: }
\end{tabular}

kategori sangat tinggi, 7 siswa atau $23,33 \%$

mendapatkan nilai dengan kategori tinggi,

dan 22 siswa atau 73,33\% mendapatkan nilai

sedang.

Tabel 2. Distribusi Frekuensi Hasil Belajar Siswa Berdasarkan KKM pada Sekolah Non Adiwiyata

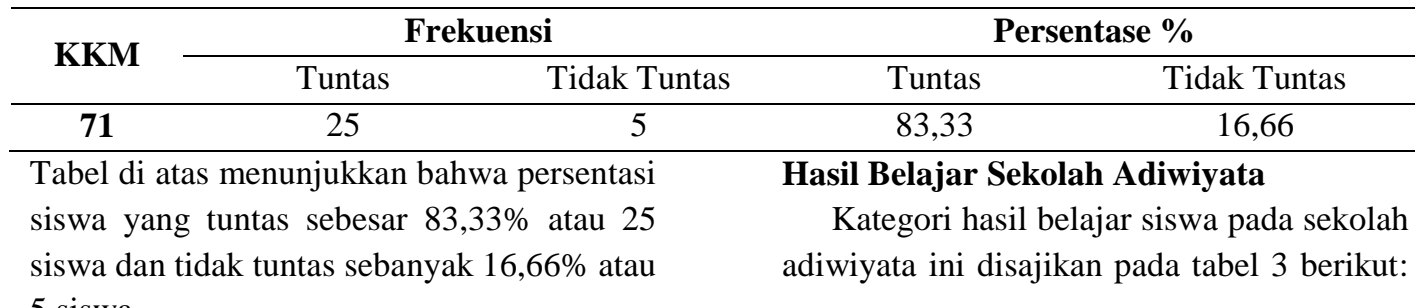

5 siswa. 
Tabel 3. Distribusi Frekuensi Kategori Hasil Belajar Siswa Pada Sekolah Adiwiyata

\begin{tabular}{ccccc}
\hline No & Interval & Kategori & Frekuensi & Persentase \% \\
\hline 1 & $90-100$ & Sangat tinggi & 2 & 6,66 \\
2 & $80-89$ & Tinggi & 15 & 50 \\
3 & $65-79$ & Sedang & 13 & 43,33 \\
4 & $55-64$ & Rendah & 0 & 0 \\
5 & $0-54$ & Sangat rendah & 0 & 0
\end{tabular}

Tabel 3 di atas menunjukkan tingkat pengetahuan siswa terhadap materi lingkungan hidup pada sekolah yang menerapkan program adiwiyata. Sebanyak 2 siswa atau $6,66 \%$ mendapatkan nilai dengan kategori sangat tinggi, 15 siswa atau 50\% mendapatkan nilai dengan kategori tinggi dan 13 siswa atau 43,33\% mendapatkan nilai sedang.

Berdasarkan kriteria ketuntasan minimal (KKM) yang berlaku di SMA Negeri 6 Bulukumba yakni 72, maka tingkat pencapaian KKM pada materi lingkungan hidup dapat dilihat pada tabel 4 berikut:

Tabel 4. Distribusi Frekuensi Hasil Belajar Siswa berdasarkan KKM pada Sekolah Adiwiyata

\begin{tabular}{ccccc}
\hline \multirow{2}{*}{ KKM } & \multicolumn{2}{c}{ Frekuensi } & \multicolumn{2}{c}{ Persentase \% } \\
\cline { 2 - 5 } Tuntas & \multicolumn{1}{c}{ Tidak Tuntas } & \multicolumn{2}{c}{ Tuntas } & Tidak Tuntas \\
\hline T2 & 27 & 3 & 90,00 & 10,00 \\
persentase siswa yang tuntas sebesar 90\% & disimpulkan bahwa terdapat perbedaan yang \\
atau 27 siswa dan tidak tuntas sebanyak 10\% & hidup siswa pada sekolah yang \\
atau 3 siswa. & melaksanakan program adiwiyata dengan \\
Hasil perhitungan diperoleh rata-rata & sekolah yang tidak melaksanakan program \\
nilai hasil belajar lingkungan hidup pada & adiwiyata di Kabupaten Bulukumba, yang \\
sekolah yang tidak menerapkan program & ditunjukkan dengan perolehan t hitung yang \\
adiwiyata sebesar 75,70 dan rata-rata nilai & sebesar 0,018 < 0,05 (H1 diterima). \\
hasil belajar lingkungan hidup pada sekolah & Perbedaan kedua hasil belajar siswa pada \\
yang menerapkan program adiwiyata & materi lingkungan hidup dapat lihat dari \\
sebesar 80,03. Dalam pengujian hipotesis & tabel 5.
\end{tabular}

Tabel 5. Analisis Perbedaan Hasil Belajar Siswa pada Sekolah Nonadiwiyata dengan Sekolah Adiwiyata

\begin{tabular}{|c|c|c|c|}
\hline No & Kategori & Sekolah Non Adiwiyata & Sekolah Adiwiyata \\
\hline 1 & Ukuran & 30 & 30 \\
\hline \multirow[t]{2}{*}{2} & Sampel & 69 & 70 \\
\hline & Nilai terendah & & \\
\hline 3 & Nilai tertinggi & 90 & 91 \\
\hline 4 & Nilai rata-rata & 75,70 & 80,03 \\
\hline 5 & $\begin{array}{l}\text { Standar } \\
\text { deviasi }\end{array}$ & 5,04 & 6,01 \\
\hline 6 & Kategori Nilai & $\begin{array}{l}22 \text { orang siswa yang } \\
\text { mempunyai nilai sedang, } 7 \\
\text { orang siswa dalam kategori } \\
\text { tinggi dan } 1 \text { orang dalam } \\
\text { kategori sangat tinggi }\end{array}$ & $\begin{array}{l}13 \text { orang siswa yang mempunyai nilai } \\
\text { sedang, } 15 \text { orang siswa dalam kategori } \\
\text { tinggi dan } 2 \text { orang dalam kategori } \\
\text { sangat tinggi }\end{array}$ \\
\hline 7 & KKM & $\begin{array}{l}\text { Terdapat } 25 \text { orang yang tuntas } \\
\text { dan } 5 \text { orang yang tidak tuntas }\end{array}$ & $\begin{array}{l}\text { Terdapat } 27 \text { orang yang tuntas dan } 53 \\
\text { orang yang tidak tuntas }\end{array}$ \\
\hline
\end{tabular}


Hasil penelitian didapatkan bahwa hasil belajar lingkungan hidup pada sekolah yang melakukan program adiwiyata lebih tinggi dibandingkan dengan hasil belajar lingkungan hidup pada sekolah yang belum menerapkan program adiwiyata. Dapat ditafsirkan bahwa program adiwiyata setidaknya memberikan pengaruh terhadap hasil belajar lingkungan hidup. Hasil penelitian ini sejalan dengan penelitian yang dilakukan oleh Referensi [8] yang menyatakan bahwa pengetahuan (kognitif), sikap (afektif), dan keterampilan (pisikomotorik) lingkungan hidup siswa Sekolah adiwiyata lebih tinggi dibanding Sekolah belum adiwiyata dan ada pengaruh positif progam adiwiyata terhadap kognitif, afektif, dan pisikomotorik lingkungan hidup siswa.

Melalui penerapan program adiwiyata, materi lingkungan hidup tidak hanya didapatkan pada mata pelajaran geografi tapi juga diajarkan pada mata pelajaran monolitik dan mata pelajaran reintegrasi. Dengan adanya kesamaan materi yang diajarkan, pemahaman siswa terhadap lingkungan hidup pastinya juga akan bertambah. Pembelajaran yang mengedepankan pengetahuan itu dapat diperoleh melalui pengalaman langsung dan tidak langsung. Semakin langsung objek yang dipelajari, maka semakin konkrit pengetahuan yang diperoleh. Semakin tidak langsung pengetahuan itu diperoleh maka semakin abstrak pengetahuan siswa [9]. Memperhatikan media dan pengalaman belajar siswa tersebut maka kedudukannya sangatlah penting dalam sistem proses belajar mengajar utamanya dalam peningkatan hasil belajar siswa.

Memperhatikan lingkungan sekolah yang sehat, nyaman, dan kondusif berkorelasi dengan hasil belajar siswa. Hal tersebut dikarenakan proses belajar mengajar memerlukan kondisi psikologis yang mendukung. Proses belajar mengajar memerlukan ruang dan lingkungan pendukung yang dapat membantu siswa dan guru agar dapat berkonsentrasi dalam belajar. Hasil penelitian ini sesuai dengan penelitian yang dilakukan oleh Referensi [10] bahwa lingkungan tempat belajar memiliki hubungan yang sangat erat dengan hasil belajar yang didapatkan oleh siswa.

Dari hasil observasi yang dilakukan, tingginya hasil belajar lingkungan hidup siswa memberikan pengaruh terhadap sikap dalam pelestarian lingkungan. Faktor yang cenderung mempengaruhi sikap dalam pelestarian lingkungan di SMA Negeri 6 Bulukumba yaitu: 1) Kecenderungan siswa bersikap peduli lingkungan karena adanya aturan yang memberikan tugas kebersihan dan jadwal pemeliharaan tanaman. 2) Kecenderungan siswa bersikap peduli karena adanya lomba kebersihan antar kelas. 3) Kecenderungan siswa bersikap peduli lingkungan karena adanya sarana dan prasarana yang mendukung untuk kegiatan pengelolaan lingkungan sekitar.

Pembinaan siswa terhadap lingkungan tidak dapat dilakukan dengan cara yang singkat, namun pembinaan terhadap hal-hal yang sederhana di lingkungan sekolah diharapkan mampu membangun pengetahuan siswa sehingga sikap dan perilaku mereka selalu menerapkan etika lingkungan hidup. Sekolah adiwiyata tidak hanya menampilkan keindahan dan kelengkapan sarana dan prasarana sekolah, tetapi juga diharapkan agar seluruh warga sekolah dapat membangun kesadaran lingkungan yang tercermin dari pengetahuan dan hasil belajar siswa itu sendiri.

\section{DAFTAR PUSTAKA}

[1]. Hamzah, S. 2010. Revitalisasi Pendidikan Lingkungan Sebagai Sebuah Keharusan yang tak Terelakkan. Bengkulu. FKIP Universitas Bengkulu.

[2] Wulandari, Ria. 2016. Met Kunjungan Lapangan Un Menanamkan Kepedulian terha Lingkungan Hidup. Jur Pedagogia. 5 (1): 67-80. 
[3] Djamin, Djanius. 2007. Pengawasan dan Pelaksanaan Undang-Undang Lingkungan Hidup. Jakarta: Yayasan Obor.

[4] Notohadiprawiro. 2006. Pendidikan Lingkungan. Yogyakarta. Universitas Gajah Mada.

[5] Sugiyono. 2009. Metode Penelitian Pendidikan, Kuantitatif, Kualitatif, $R \& D$. Bandung. Alfabeta.

[6] Hidayati, Nanik., Tukiman Taruna dan Hartuti Purnaweni. Perilaku Warga Sekolah dalam Program Adiwiyata di SMK Negeri 2 Semarang. Prosiding Seminar Nasional Pengelolaan Sumberdaya Alam dan Lingkungan 2013. 149-154.

[7] Hidayatun, Nur Latifah. 2016. Studi Deskriptif Pelaksanaan Program Adiwiyata Di SD Muhamadiyah Tonggalan Klaten. Jurnal Pendidikan Guru Sekolah Dasar. 5 (20): 945- 958.

[8] Brophy, J. 2004. Motivating Student to Learn (2nd ed).
London: Lawrence Erlbaum Associates, Publisher.

[9] Sanjaya, W. 2006. Strategi Pembelajaran, Berorientasi Standar Proses Pendidikan. Jakarta. Kencana Prenada Media Grup.

[10] Rahmawati, Ria Risty. 2013. Hubungan Pasilitas dan Lingkungan Belajar Siswa Dengan Prestasi Belajar Siswa SMA Negeri 3 Sukoharjo. Surakarta: FKIP Universitas Sebelas Maret. 